\title{
Suppression of Bipolaris Stem Rot on Cactus by Heat-inactivated Conidial Suspension of Bipolaris cactivora
}

\author{
Min-Ok Choi, Sang Gyu Kim and Young Ho Kim* \\ Department of Agricultural Biotechnology, Seoul National University, Seoul 151-921, Korea \\ (Received on April 28, 2010; Accepted on August 2, 2010)
}

The heat-inactivated (at $121^{\circ} \mathrm{C}$ for $20 \mathrm{~min}$ ) conidial suspension of Bipolaris cactivora (HICS) was evaluated for the control of Bipolaris stem rot of cactus caused by $B$. cactivora. Severe rot symptoms were developed on the cactus stem discs inoculated with $B$. cactivora from 5 days after inoculation. However, only small brownish spots developed on the stem discs treated with HICS 2 days prior to the pathogen inoculation. HICS also reduced symptom development on cactus stem discs inoculated with other fungal pathogens such as Alternaria alternata, Colletotrichum gloeosporioides, and Fusarium oxysporum, suggesting its disease-inhibitory efficacy may not be pathogen-specific. HICS significantly reduced severities of the stem rot disease on several cactus species including Hylocereus trigonus, Cereus peruvianus, Chamaecereus silvestrii and Gymnocalycium mianovichii, but not on Cereus tetragonus. Extensive wound periderms were formed in the stem tissues of inoculation and/or wounding sites on $C$. peruvianus treated with HICS alone or prior to the pathogen inoculation, but not on $C$. tetragonus, indicating the structural modifications may be related to the mechanism of disease suppression by HICS. HICS also reduced the disease development on the grafted cactus $(H$. trigonus stock and $G$ mianovichii scion) with the control efficacy nearly equivalent to the application of a commercial fungicide. All of these results suggest HICS can be used as an environmentalfriendly agent for the control of the cactus stem disease.

Keywords : Bipolaris cactivora, cactus, disease suppression, heat-inactivated conidial suspension, wound periderm formation

The Cactaceae consists of morphologically heterogeneous groups including three subfamilies (Cactoideae, Opuntioideae and Pereskioideae), 100 genera and over 1500 species, most of which are natives of America with dry and hot climatic conditions (Cruz et al., 1997). Recently, cactus farms in Korea, Japan and China have produced some interesting forms of cacti called grafted cacti by grafting

\footnotetext{
*Corresponding author.

Phone) +82-2-880-4675, FAX) +82-2-873-2317

E-mail)yhokim@snu.ac.kr
}

two different cactus species including photosynthetic stocks and non-photosynthetic scions to ensure the growth of the decorative colored scions. Currently Korea is the main cultivating region of the grafted cactus, which comprises about $70 \%$ of the world trading market (Song et al., 2009a, 2009b).

Since the grafted cactus is cultivated at warm temperature and high humidity during the whole growing season in greenhouses, a variety of fungal and bacterial diseases are frequently found in the cactus farms in Korea (Chang et al., 1998; Choi et al., 2010; Hyun et al., 1998; Kim et al., 2000; Kim et al., 2007). Bipolaris stem rot caused by Bipolaris cactivora is one of the serious fungal diseases in cactus fields.

Bipolaris cactivora is a necrotrophic pathogen that causes a top or basal rot on various cactus species including Cephalocereus mezcalaensis, Cereus peruvianus, Cereus tetragonus, Chamaecereus silvestrii, Gymnocalycium mianovichii, Hylocereus undatus, and H. trigonus (Chase, 1982; Hyun et al., 2001; Taba et al., 2007). The symptoms are initial yellow or brown spots, which are rapidly enlarged with time to shrunken or water-soaked black lesions (Chang et al., 1998; Durbin et al., 1955; Kim et al., 2004a). The cactus disease has been controlled primarily by synthetic fungicides, showing an immediate fungicidal effect. However, there are concerns about the occurrence of pathogens resistant to the fungicides derived from their consecutive uses and also about their harmful effects to environments and human and animal health. Thus, the development of other control measures alternative to synthetic pesticides is considered for the practical control in farms (Heivieux et al., 2002).

Recently several strategies are considered for substituting the chemical control, one of which is the use of metabolites or compounds from biological resources. Previous studies on these control agents have included cell-free germination fluid of Botrytis cinerea, heat-killed conidial suspension of Bipolaris spp. and Drechslera tritici-repentis, heat-killed bacterial cells of Pseudomonas spp., exopolysaccharides (EPS) extracted from Xanthomonas sp., intercellular fluid of tobacco leaves, which were reported as effective control agents against bacterial and fungal diseases on coffee, 
wheat, and barley (Bach et al., 2003; Heale et al., 1982; Lozano and Sequeira, 1969; Rathmell and Sequeira, 1975). In this study, the control of Bipolaris stem rot on cactus using the heat-inactivated conidial suspension (HICS) of its causal fungal pathogen Bipolaris cactivora was examined to develop an eco-friendly control measure for the cactus stem rot disease.

\section{Materials and Methods}

Pathogens and pathogen inoculation. One of $B$. cactivora isolates (CC1-5), obtained from cactus greenhouses at Goyang in 2009 was used for this study after examining their pathogenicity on grafted cactus (unpublished data). Alternaria alternata CD2-7A, Colletotrichum gloeosporioides C-1 (Glomerella cingulata $\mathrm{C}-1$ ) and Fusarium oxysporum CFb4-2 were applied for inducing the other cactus stem diseases, which were used in the previous studies (Choi et al., 2010; Han, 2010; Kim and Kim, 2002). The fungal isolates were cultured on V8 juice agar at $25^{\circ} \mathrm{C}$ in the light for 7-14 days. After the fungal culturing, $10 \mathrm{ml}$ sterile distilled water (SDW) was added to the culture plates, which were scraped with a spatula to make conidial suspensions. The conidial suspensions were filtered through two layers of Mira cloth to remove mycelial and cultural debris and diluted with SDW, adjusting their concentration to $1 \times 10^{5}$ conidia/ml using a hemacytometer. For the fungal inoculation on cactus stem discs, $20 \mu$ l of each conidial suspension was dropped on the center of a cactus stem disc (0.5 cm in thickness). Also for inoculation of B. cactivora CC1-5 on grafted cacti, $1 \mathrm{ml}$ of the conidial suspension was sprayed on the 3-month-old Hylocereus trigonus-Gymnocalycium mianovichii grafted cactus plants (hereafter termed as $\mathrm{H}-\mathrm{G}$ grafted cactus). Cactus stem discs and the H-G grafted cacti inoculated with the fungal conidial suspensions were incubated at $25^{\circ} \mathrm{C}$ under 12-hr photoperiod in a growth chamber and at $20-25^{\circ} \mathrm{C}$ in a greenhouse, respectively. Symptom development was examined daily from one day after inoculation.

Preparation of heat-inactivated conidial suspension (HICS) from the culture of $B$. cactivora CC1-5. $B$. cactivora $\mathrm{CC} 1-5$ was cultured on $\mathrm{V} 8$ juice agar at $25^{\circ} \mathrm{C}$ in the light for 7 days. Ten milliliters of SDW was added on the fungal cultures and conidia were harvested by scraping the culture surface with a spatula. The conidial suspension was filtered through two layers of Mira cloth and adjusted to $1.0 \times 10^{6}$ conidia/ml with SDW using a hemacytometer, and diluted 10 and 100 times to make the conidial suspensions of $1.0 \times 10^{5}$ conidia $/ \mathrm{ml}$ and $1.0 \times 10^{4}$ conidia $/ \mathrm{ml}$ in concentration, respectively. The conidial suspensions were sterilized by autoclaving at $121^{\circ} \mathrm{C}, 15 \mathrm{psi}$ for $20 \mathrm{~min}$ to make HICS.

Examination of optimum concentration and treatment timing of HICS. In this experiment, three different timings of HICS treatment were designed, including pre-treatment ( 2 days before the pathogen inoculation), simultaneous treatment (at the same time of the pathogen inoculation), and post-treatment ( 2 days after the pathogen inoculation), for which HICS was applied at three different concentrations of $1.0 \times 10^{6}$ conidia/ml, $1.0 \times 10^{5}$ conidia $/ \mathrm{ml}$ and $1.0 \times 10^{4}$ conidia/ml. H. trigonus stems were surface-sterilized with $70 \%$ ethanol for $1 \mathrm{~min}$ and $1 \%$ sodium hypochlorite for $30 \mathrm{sec}$, and rinsed in SDW. They were cut transversely with a sterilized razor blade to make stem discs of $0.5 \mathrm{~cm}$ in thickness, on which $100 \mu$ of HICS was dropped in the central pith region. The stem discs were inoculated with the conidial suspension of $B$. cactivora $\mathrm{CC} 1-5$ as mentioned above. They were placed on moistened filter paper in Petri plates and incubated at $25^{\circ} \mathrm{C}$ under the $12-\mathrm{h}$ photoperiod in an incubation chamber. Rot symptom development on the stem discs was examined daily up to 15 days after inoculation.

Effect of HICS on the suppression of various cactus stem diseases. HICS was tested for the suppression of various stem diseases caused by $A$. alternata, $B$. cactivora, $C$. gloeosporioides and F. oxysporum on the stem discs of H. trigonus. A hundred microliters of HICS was dropped on stem discs of H. trigonus, and placed on moistened filter paper in Petri plates at $25^{\circ} \mathrm{C}$ under $12 \mathrm{~h}$ photoperiod. After 2 days of treatment, the stem disks were inoculated with $20 \mu \mathrm{l}$ of the conidial suspensions $\left(1 \times 10^{5}\right.$ conidia/ml $)$ of the pathogen isolates such as $A$. alternata CD2-7A, $B$. cactivora CC1-5, C. gloeosporioides $\mathrm{C}-1$ and $F$. oxysporum $\mathrm{CFb} 4-2$ as mentioned above. The cactus stem disks inoculated with the pathogens were placed on moistened filter paper in Petri plates at $25^{\circ} \mathrm{C}$ under 12-h photoperiod in an incubation chamber. Symptom development was examined daily up to 15 days after inoculation.

Effect of HICS on the disease suppression of Bipolaris stem rot on different cactus species. HICS was tested for the disease suppression on the stem discs of several cactus species including three stock cacti ( $C$. peruvianus, $C$. tetragonus and $H$. trigonus) and two scion cacti ( $C$. silvestrii and G. mianovichii) using the HICS at the concentration of $1.0 \times 10^{5}$ conidia $/ \mathrm{ml}$ that was shown optimum in the above experiment. One milliliter of HICS was treated on stem discs of Cereus spp. and $100 \mu$ of HICS on stem discs of $H$. trigonus and other scion cactus stems, and placed on moistened filter paper in Petri plates at $25^{\circ} \mathrm{C}$ under 12-h photoperiod. After 2 days of treatment, the stem 
disks were inoculated with $20 \mu \mathrm{l}$ of the conidial suspension $\left(1 \times 10^{5}\right.$ conidia $\left./ \mathrm{ml}\right)$ of $B$. cactivora $\mathrm{CC} 1-5$. The stem disks were placed on moistened filter paper in Petri plates at $25^{\circ} \mathrm{C}$ under 12-h photoperiod in an incubation chamber. Symptom development was examined daily up to 15 days after inoculation.

Mechanism of the disease suppression by HICS. As the two Cereus species, C. peruvianus and C. tetragonus, showed different efficacy of HICS in the above experiment, these two cactus plants were used for examining the mechanism of the disease suppression by HICS. For this, the cactus stems were surface-sterilized in $1 \%$ sodium hypochlorite for $30 \mathrm{sec}$ and $70 \%$ ethanol for $1 \mathrm{~min}$, rinsed twice in sterile water and cut transversely with a sterilized razor blade to make stem discs of $0.5 \mathrm{~cm}$ in thickness. Stem discs were treated with $100 \mu$ of HICS and placed on moistened filter paper in Petri plates, incubating at $25^{\circ} \mathrm{C}$ under 12-h photoperiod. For pathogen inoculation, $20 \mu \mathrm{l}$ of the fungal conidial suspension $\left(1 \times 10^{5}\right.$ conidia $\left./ \mathrm{ml}\right)$ was inoculated on the pith region at the center of cactus stem disks at two days after HICS treatment. The inoculated stem discs were incubated further at the same incubation conditions mentioned above. After 8 and 13 days of incubation, the inoculated tissues were excised longitudinally and hand-sectioned c.a. $20 \mu \mathrm{m}$ in thickness with a razor blade. The sections were observed under a light microscope (Axiophot, Zeiss, Germany) after staining with $0.1 \%$ toluidine blue $\mathrm{O}$.

Comparison of HICS effect on the disease suppression with other treatments. In this experiment, the efficacy of HICS in suppressing the Bipolaris stem rot was compared with those of carborundum and fungicide (iminoctadine triacetate) treatments which were known to induce plant defense reaction against the chili pepper anthracnose caused by Colletotrichum acutatum (Kim et al., 2008) and to be one of commercial fungicides effective in suppressing spore germination and mycelia growth of the pathogen, respectively (Choi and Kim, unpublished data). Threemonth-old H-G grafted cacti cultivated in a cactus greenhouse at Goyang, Korea were used in this experiment, in which the three materials, HICS, carborundum \#400 (Hayashi Pure Chemical, Japan), and a commercial fungicide iminoctadine triacetate (Dongbang Agro, Korea), were applied to examine their effectiveness in reducing the disease development. HICS was prepared as mentioned above and the suspensions of carborundum and iminoctadine triacetate were prepared at concentrations of $0.5 \%$ and $0.3 \%$ in SDW, respectively. The grafted cacti were washed in a neutral detergent and rinsed with distilled water two times. The grafted cacti were sprayed with $1 \mathrm{ml}$ of the suspensions

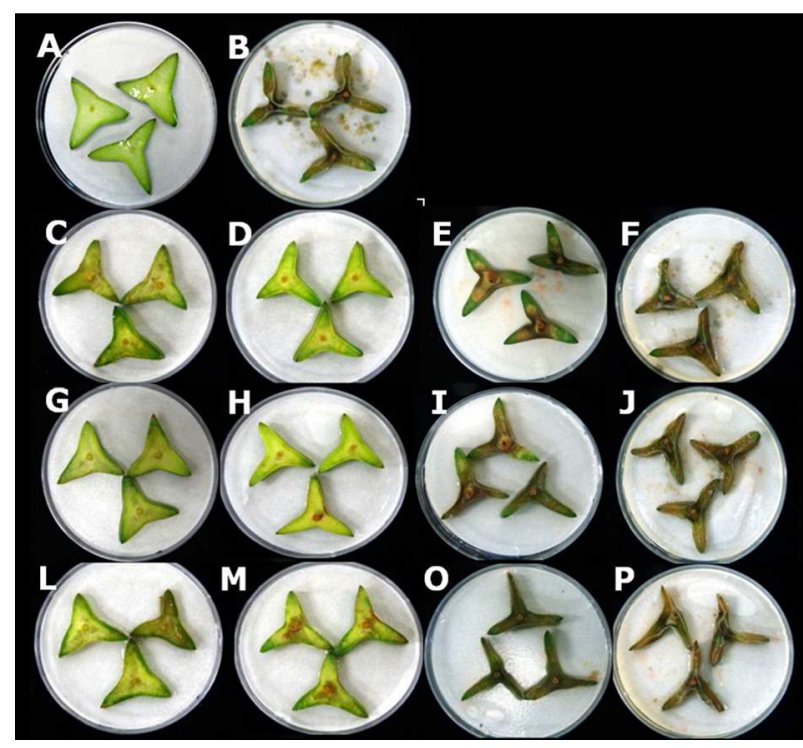

Fig. 1. Effect of heat-inactivated conidial suspension of Bipolaris cactivora (HICS) on rot symptom development on stem discs of Hylocereus trigomus inoculated with B. cactivora at 5 days after inoculation. (A) no pathogen inoculation control, (B) pathogen inoculation only, (C, G, L) HICS treatment only, (D, H, M) HICS treatment at 2 days before inoculation (pre-treatment), (E, I, O): simultaneous HICS treatment, (F, J, P) HICS treatment at 2 days after inoculation (post-treatment). HICS concentrations: $1 \times 10^{4}$ conidia/ml (C-F), $1 \times 10^{5}$ conidia/ml (G-J), $1 \times 10^{6}$ conidia/ $\mathrm{ml}(\mathrm{L}-\mathrm{P})$.

with 5 replications for each treatment. They were placed in sterilized plastic containers with two layers of moistened paper towel lined on the bottom to maintain humidity, incubating at $20^{\circ} \mathrm{C}$ under 12 -h photoperiod in an incubation chamber. After 2 days of treatment, the cactus plants were inoculated with the conidial suspension of B. cactivora $\mathrm{CC} 1-5$ as mentioned above after pin-prick wounding (5 $\mathrm{mm}$ in depth) on the scion cactus stems. Plants inoculated with the pathogen alone and treated with distilled water only were used as positive and negative controls. The inoculated plants were kept at $20^{\circ} \mathrm{C}, 90 \% \mathrm{RH}$ under $12-\mathrm{h}$ photoperiod for $24 \mathrm{~h}$ and then covered with a lid. Symptom development on the cactus stems was observed daily up to 3 weeks after inoculation.

\section{Results}

Optimal concentration and timing of HICS treatment for the suppression of the stem rot symptom development. Symptoms of initial small brownish spots were developed on the stem discs of $H$. trigonus at 2 days after inoculation with the conidial suspension of the pathogen and gradually enlarged and finally rotted the whole stem discs at 5 days after inoculation, while no rot symptoms were developed on 
Table 1. Effect of pre-treatment with heat-inactivated conidial suspension of Bipolaris cactivora CC1-5 (HICS) on the development of cactus stem diseases caused by Alternaria alternata (AA), B. cactivora (BC), Colletotrichum gloeosporioides (CG) and Fusarium oxysporum (FO)

\begin{tabular}{lcccc}
\hline \hline \multirow{2}{*}{ Treatment } & \multicolumn{4}{c}{ Symptom severity index $^{\mathrm{a}}$} \\
\cline { 2 - 5 } & \multicolumn{4}{c}{ Cactus diseases } \\
\cline { 2 - 5 } & $\mathrm{AA}$ & $\mathrm{BC}$ & $\mathrm{CG}$ & $\mathrm{FO}$ \\
\hline $\begin{array}{l}\text { Pathogen } \\
\text { inoculation (PI) }\end{array}$ & $3.7 \pm 0.6^{\mathrm{b}}$ & $5.0 \pm 0.0$ & $4.0 \pm 0.0$ & $5.0 \pm 0.0$ \\
HICS before PI & $1.7 \pm 0.6$ & $0.3 \pm 0.6$ & $2.0 \pm 1.0$ & $2.7 \pm 0.6$ \\
HICS only & $0.0 \pm 0.0$ & $0.0 \pm 0.0$ & $0.0 \pm 0.0$ & $0.0 \pm 0.0$ \\
SDW & $0.0 \pm 0.0$ & $0.0 \pm 0.0$ & $0.0 \pm 0.0$ & $0.0 \pm 0.0$
\end{tabular}

${ }^{\mathrm{a}}$ Symptom severity index indicates that $0=$ no symptom or yellowish discolored area less than 10\%,1=yellowish discolored area more than $10 \%$ or small brownish spot, $2=$ water-soaked area less than $50 \%, 3=$ water-soaked area more than $50 \%, 4=$ brownish or blackish rotten area less than $50 \%$ and $5=$ brownish or blackish rotten area more than $50 \%$ to whole stem disc rotten.

${ }^{\mathrm{b}}$ Pathogen for each of cactus diseases was used for inoculation.

${ }^{\circ}$ Values are means and standard deviations of 3 replications.

"Examined at 5 days after inoculation.

stem discs treated with SDW (Fig. 1A, B). The stem discs treated with HICS alone (Fig. 1C, G, L) and 2 days prior to pathogen inoculation (Fig. 1D, H, M), regardless of its concentrations, showed no or minimal disease development. In HICS treatment, only small brownish lesions or watersoaking symptoms were produced in the center of the stem discs at the highest concentration $\left(1 \times 10^{6}\right.$ conidia $\left./ \mathrm{ml}\right)$ (Fig. 1M). On the other hand, the disease-inhibitory effects of HICS were not shown on the stem discs treated with HICS simultaneously at (Fig. 1E, I, O) and 2 days after the pathogen inoculation (Fig. 1F, J, P).

Effect of HICS on the suppression of various cactus stem diseases. Severe rot symptoms were produced on the stem discs by the inoculations of all fungal pathogens tested
Table 2. Effect of pre-treatment with heat-inactivated conidial suspension of Bipolaris cactivora CC1-5 (HICS) on the development of Bipolaris stem rot symptoms on stem discs of several cactus species

\begin{tabular}{lccccc}
\hline \hline \multirow{2}{*}{ Treatment } & \multicolumn{5}{c}{ Symptom severity index $^{\mathrm{a}}$} \\
\cline { 2 - 6 } & \multicolumn{5}{c}{ Cactus species $^{\mathrm{b}}$} \\
\cline { 2 - 6 } & $\mathrm{CP}$ & $\mathrm{CT}$ & $\mathrm{HT}$ & $\mathrm{CS}$ & $\mathrm{GM}$ \\
\hline $\begin{array}{l}\text { Pathogen } \\
\text { inoculation (PI) }\end{array}$ & $5.0 \pm 0.0^{\mathrm{c}}$ & $5.0 \pm 0.0$ & $5.0 \pm 0.0$ & $5.0 \pm 0.0$ & $5.0 \pm 0.0$ \\
HICS before PI & $0.7 \pm 0.6$ & $5.0 \pm 0.0$ & $0.7 \pm 0.6$ & $1.0 \pm 0.0$ & $2.7 \pm 0.6$ \\
HICS only & $0.0 \pm 0.0$ & $0.0 \pm 0.0$ & $0.0 \pm 0.0$ & $0.0 \pm 0.0$ & $0.0 \pm 0.0$ \\
SDW & $0.0 \pm 0.0$ & $0.0 \pm 0.0$ & $0.0 \pm 0.0$ & $0.0 \pm 0.0$ & $0.0 \pm 0.0$ \\
\hline
\end{tabular}

${ }^{a}$ Symptom severity index indicates that $0=$ no symptom or yellowish discolored area less than 10\%,1=yellowish discolored area more than $10 \%$ or small brownish spot, $2=$ water-soaked area less than $50 \%$, $3=$ water-soaked area more than $50 \%, 4=$ brownish or blackish rotten area less than $50 \%$ and $5=$ brownish or blackish rotten area more than $50 \%$ to whole stem disc rotten.

${ }^{\mathrm{b}}$ Cactus species; CP: Cereus peruvianus, CT: Cereus tetragonus, HT: Hylocereus trigonus, CS: Chaemacereus silvestrii, GM: Gymnocalycium mianovichii.

${ }^{\mathrm{c}}$ Values are means and standard deviations of 3 replications.

"Examined at 5 days after inoculation.

in this experiment including A. alternata, B. cactivora, $C$. gloeosporioides and $F$. oxysporum. Application of HICS before the pathogen inoculations significantly reduced the symptom development of the diseases with some variations depending on the causal pathogens (Table 1). The most reduction of rot symptom severity by HICS occurred in the disease caused by $B$. cactivora, the least in the disease caused by $F$. oxysporum, and in the middle for the other cactus stem diseases.

Effect of HICS on the disease suppression on various cactus species. HICS was tested for its effectiveness in reducing Bipolaris stem rot caused by $B$. cactivora on several cactus species such as C. peruvianus, C. tetragonus,
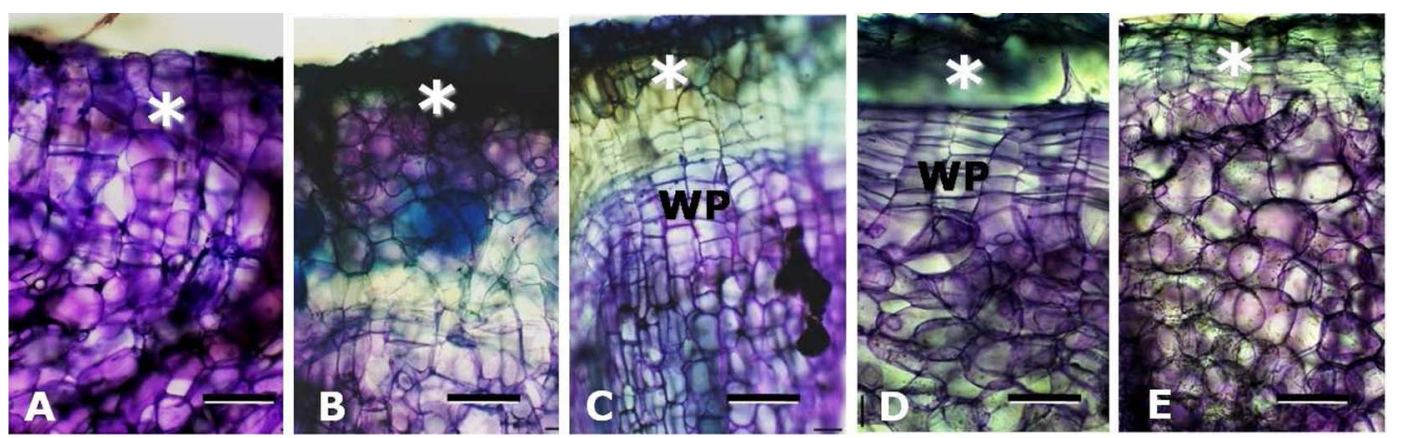

Fig. 2. Light micrographs of hand-cut sections of cactus stems of Cereus peruvianus (A-D) and C. tetragonus (E) with treatment of heatinactivated conidial suspension of Bipolaris cactivora (HICS) (C-D) and inoculation with B. cactivora (B, C) at 8 days (A-C) and 13 days (D, E) after wounding/inoculation. Asterisks: inoculation/wounding sites; WP: wound periderm. Note periclinal cell divisions in the wound periderm. Bars: $100 \mu \mathrm{m}$. 
Table 3. Comparison of the effects of pre-treatment with heatinactivated conidial suspension of Bipolaris cactivora CC1-5 (HICS) on the development of Bipolaris stem rot of grafted cactus with other treatments

\begin{tabular}{lcc}
\hline \hline Treatment $^{\mathrm{a}}$ & Disease index $^{\mathrm{b}}$ & Control effect (\%) $^{\mathrm{c}}$ \\
\hline Pathogen inoculation (PI) & $4.0 \pm 1.4 \mathrm{X}^{\mathrm{d}}$ & - \\
HICS spray before PI & $1.2 \pm 1.6 \mathrm{YZ}$ & 71.4 \\
$\begin{array}{l}\text { Carborundum spray } \\
\text { before PI }\end{array}$ & $3.2 \pm 2.0 \mathrm{XY}$ & 23.8 \\
Fungicide spray before PI & $0.0 \pm 0.0 \mathrm{Z}$ & 100.0 \\
\hline
\end{tabular}

${ }^{a}$ Treated 2 days before the pathogen inoculation.

${ }^{\mathrm{b}}$ Disease index: $0=$ no symptom, $1=$ small brownish spot on scion cactus with no rot symptoms, $2=$ rot symptoms less than $30 \%$ of , $3=$ rot symptoms $30-60 \%, 4=$ rot symptoms $60-90 \% 5=$ the whole scion and stock rotten. Values are means \pm standard deviations of 5 replications.

Control effect $(\%)=(1-$ disease index of treatment/disease index of PI) $\times 100$.

${ }^{\mathrm{d}}$ Values followed by the same letters are not significantly different at $P=0.05$ by Duncan's multiple range test.

H. trigonus, C. silvestrii, and G. mianovichii. With the pathogen inoculation alone, the stem discs of all cactus species tested were water-soaked, discolored brownish and finally rotten severely (Table 2). The cactus stem discs treated with HICS 2 days before the pathogen inoculation had no or minimal rot symptoms in $C$. peruvianus, $H$. trigonus and $C$. silvestrii, and significantly reduced rot symptoms in $G$. mianovichii. For C. tetragonus, however, HICS showed no inhibitory effect on the disease development; severe water-soaked and rotten symptoms appeared on the stem discs like the pathogen inoculation alone. In all cactus species tested, no symptoms were produced on the stem discs treated with HICS and SDW.

Mechanism of control effects by HICS. The two cactus species, $C$. peruvianus and $C$. tetragonus, were totally different each other in the effect of HICS on the suppression of the symptom development; No or little rot symptoms developed on $C$. peruvianus, but severe rot symptoms on $C$. tetragonus (Table 2). Light microscopy of the stem tissues at the inoculation/wounding sites showed no or little indication of wound peridem formation in healthy cactus stem tissues with wounding alone (with no HICS treatment) at 8 days after wounding (Fig. 2A). The stem tissues inoculated with the pathogen alone with no HICS treatment in C. peruvianus (Fig. 2B) and in C. tetragonus (data not shown) were damaged and darkened with deformed parenchyma cells beneath the inoculation sites at 8 days after inoculation. Light microscopy of $C$. peruvianus stem tissues treated with HICS before the pathogen inoculation showed the extensive formation of wound periderm under the wounding sites at 8 days after treatment, characterized by cell layers resulting from periclinal cell divisions (Fig. 2C). Also in $C$. peruvianus, HICS treatment alone induced an extensive wound peridem formation under the wounding sites at 13 days after treatment (Fig. 2D); however, no or little wound periderm was formed in C. tetragonus treated with HICS alone (Fig. 2E).

Comparison of the HICS effects on the disease development with other treatments. The effect of HICS on the disease development was compared with those of other treatments such as carborundum and commercial fungicide treatments (Table 3). Cactus stems with pathogen inoculation alone showed a severe stem rot (with disease index of 4.0) at 7 days after inoculation. The whole grafted cactus stems including even stock stems were rotten at 12 days after inoculation. Application of the HICS 2 days prior to the pathogen inoculation significantly reduced the disease severity, having only small brownish spots on the scion stems of $G$. mianovichii. Cacti treated with carborundum showed more rotting than HICS treatment, although it significantly reduced rotten symptoms on stems relative to the pathogen inoculation alone. No symptoms were produced on the stems treated with the fungicide prior to the pathogen inoculation.

\section{Discussion}

Bipolaris cactivora has been known as a causal agent of the cactus stem rot on various cactus species in Korea, Japan and USA (Chang et al., 1998; Chase, 1982; Durbin et al., 1955; Taba et al., 2007). In Korea, it was reported as a serious disease occurring especially on the H-G grafted cactus, comprising up to $77 \%$ infections at the cactus fields (Chang et al., 1998; Hyun et al., 2001). Thus, it is required that this disease should be controlled effectively for the successful cultivation of the grafted cactus.

When the conidial suspension of $B$. cactivora was sterilized by autoclaving at $121^{\circ} \mathrm{C}$ for $20 \mathrm{~min}$, it was discovered in this study that the heat-inactivated conidial suspension (HICS) lost its virulence but had an inhibitory effect on the development of stem diseases not only caused by $B$. cactivora but also by other cactus stem pathogens such as species of Alternaria, Colletotrichum and Fusarium. This suggests the effectiveness of HICS in the disease suppression may not be pathogen-specific.

The disease inhibitory effect of HICS was only noticed in its pre-treatment, but not in simultaneous and post-treatments in our study. These aspects suggest that it should take a certain period of time to have HICS treatment be effective in suppressing the pathogen infection. The plant defense responses responsible for the disease suppression by HICS appeared to be the wound periderm formation as revealed 
in the comparison of its disease-inhibitory efficacies between $C$. peruvianus and $C$. tetragonus. Wound periderm was extensively and poorly formed in the stem tissues of the former and the latter cacti, in correspondence with the strong and weak disease suppression capabilities of HICS, respectively. These findings are in agreement with those of Bach et al. (2003), in which the inhibition of the leaf spot disease on wheat by the applications of heat-inactivated conidial suspensions of Bipolaris bicolor, B. sorokiniana and Drechslera tritici-repentis is due to the induction of local and systemic resistance, but not by their antifungal activities.

Wound periderm is a histological defense structure formed in response to wounding and invasion by parasites (Biggs and Britton, 1988; Prusky et al., 2000; Smith, 1982). Similar structural alterations like wound periderm formation are found in C. peruvianus stems and chili pepper fruit as resistance responses to the pathogen infections (Kim and Kim, 2002; Kim et al., 2004b, 2008). Wounding itself could induce the wound periderm formation as a healing process in cactus stem discs; however, it may have been stimulated by the HICS treatment in our study.

Wound periderm consists of three different tissues, phellem, phellogen and phelloderm, like natural periderm, constituting cork layers (Sabba and Lulai, 2002). The cork layers are histological defense structures induced and formed beyond the point of various pathogen infection, inhibiting further pathogen invasion and blocking the flow of toxic substances, water and nutrients required for the disease development (Agrios, 2005). All of these aspects suggest that the reduction of the disease severity by HICS may be due to the enhanced formation of wound periderm, an important defense structure that can prevent pathogen invasion and heal wound (Taylor and Whitelaw, 2001).

HICS reduced the disease development on the grafted cactus (H. trigonus stock and G. mianovichii scion) with the control efficacy nearly equivalent to the application of a commercial fungicide (iminoctadine triacetate). In this experiment, HICS treatment alone produced no harmful effect (phytotoxicity) to cactus plants, while yellow to brownish mild lesions were produced on $G$. mianovichii scions treated with the chemical fungicide (Choi and Kim, unpublished data), suggesting HICS may be used for the control of the stem rot more safely than the fungicide. Considering all of the characters of HICS (induction of resistance with high control efficacy and safeness to the plant with little harmfulness to environments and man and animal health), therefore, it has a high potential to be developed as biological agent for controlling the cactus stem diseases.

\section{Acknowledgement}

This study was financially supported by Technology Development Program for Agriculture and Forestry, Ministry for Food, Agriculture, Forestry and Fisheries, Republic of Korea.

\section{References}

Agrios, G N. 2005. Plant Pathology, Fifth Edition. San Diego, CA: Elsevier Academic Press. 922 pp.

Bach, E. E., Barros, B. C. and Kimati, H. 2003. Induced resistance against Bipolaris bicolor, Bipolaris sorokiniana and Drechslera tritici-repentis in wheat leaves by xantham gum and heat-inactivated conidial suspension. J. Phytopathol. 151:411418.

Biggs, A. R. and Britton, K. O. 1988. Presymptom histopathology of peach trees inoculated with Botryosphaeria obtusa and Botryosphaeria dothidea. Phytopathology 78:1109-1118.

Chang, M., Hyun, I. H. and Lee, Y. H. 1998. Bipolaris stem rot of cactus caused by Bipolaris cactivora (Petrak) Alcorn. Korean J. Plant Pathol. 14:661-663.

Chase, A. R. 1982. Stem rot and shattering of Easter cactus caused by Drechslera cactivora. Plant Dis. 66:602-603.

Choi, M.-O., Kim, S. G, Hyun, I.-H., Kim, J. H., Cho, C.-H., Park, M. S. and Kim, Y. H. 2010. First report of black spot caused by Alternaria alternata on grafted cactus. Plant Pathol. J. 26:80-82.

Cruz, M. D. L., Ramirez, F. and Hernandez, H. 1997. DNA Isolation and amplification from cacti. Plant Mol. Biol. Rep. 15: 319-325.

Durbin, R. D., Davis, L. H. and Baker, K. F. 1955. A Helminthosporium stem rot of cacti. Phytopathology 45:509-512.

Han, M. H. 2010. Biological characteristics of stem pathogen of Hylocereus trigonus, Fusarium oxysporum and its biological control. M.S. Thesis, Seoul National University, Seoul, Korea. $72 \mathrm{pp}$.

Heale, J. B., Dodd, K. S. and Gahan, P. B. 1982. The induced resistance response of carrot root slices to heat-killed conidia and cell-free germination fluid of Botrytis cinerea Pers. ex Pers. Ann. Bot. 49:847-857.

Heivieux, V., Yaganza, E. S., Arul, J. and Tweddell, R. J. 2002. Effect of organic and inorganic salts on the development of Helminthosporium solani, the causal agent of potato silver scurf. Plant Dis. 86:1014-1018.

Hyun, I. H., Lee, S. D., Hwang, B. C., Ko, K. I., Chung, H. S. and Kim, B. K. 2001. Occurrence of stem rot caused by Bipolaris cactivora on different species of cactus and its pathogenicity. Res. Plant Dis. 7:56-59.

Hyun, I. H., Lee, S. D., Lee, Y. H. and Heo, N. Y. 1998. Mycological characteristics and pathogenicity of Fusarium oxysporum Schlecht. emend. Snyd. \& Hans. causing stem rot of cactus Korean J. Plant Pathol. 14:463-466.

Kim, J. H., Jeoung, M. I., Hyun, I. H. and Kim, Y. H. 2004a. Potential biotypes in Korean isolates of Bipolaris cactivora associated with stem rot of cactus. Plant Pathol. J. 20:165171. 
Kim, J. H., Jeon, Y. H., Kim, S. G. and Kim, Y. H. 2007. First report on bacterial soft rot of graft-cactus Chamaecereus silvestrii caused by Pectobacterium carotovorum subsp. carotovorum in Korea. Plant Pathol. J. 23:314-317.

Kim, K.-H., Yoon, J.-B., Park, H.-G., Park, E. W. and Kim, Y. H. 2004b. Structural modifications and programmed cell death of chili pepper fruit related to resistance responses to Colletotrichum gloeosporioides infection. Phytopathology 94:12951304.

Kim, S. G., Kim, Y.-H., Kim, H.-T. and Kim, Y. H. 2008. Effect of delayed inoculation after wounding on the development of anthracnose disease caused by Colletotrichum acutatum on chili pepper fruit. Plant Pathol. J. 24:392-399.

Kim, Y. H., Jun, O. K., Sung, M. J., Shin, J. S., Kim, J. H. and Jeoung, M. I. 2000. Occurrence of Colletotrichm stem rot caused by Glomerella cingulata on graft-cactus in Korea. Plant Pathol. J. 16:242-245.

Kim, Y. H. and Kim, K.-H. 2002. Abscission layer formation as a resistance response of Peruvian apple cactus against Glomerella cingulata. Phytopathology 92:964-969.

Lozano, J. C. and Sequeira, L. 1969. Prevention of the hypersensitive reaction in tobacco leaves by heat-killed bacterial cells. Phytopathology 60:875-879.

Prusky, D., Koblier, I., Ardi, R., Beno-Moalem, D., Yakoby, N. and Keen, N. T. 2000. Resistance mechanisms of subtropical fruits to Colletotrichum gloeosporioides. In: Colletotrichum: Biology, Pathology, and Control, ed. by J. A. Bailey and M. J. Jeger, pp. 232-244. CAB International, Wallingford, UK.

Rathmell, W. G. and Sequeira, L. 1975. Induced resistance in tobacco leaves: The role of inhibitors of bacterial growth in the intercellular fluid. Physiol. Plant Pathol. 5:65-73.

Sabba, R. P. and Lulai, E. C. 2002. Histological analysis of the maturation of native and wound periderm in potato (Solanum tuberosum L.) tuber. Ann. Bot. 90:1-10.

Smith, D. A. 1982. Toxicity of phytoalexins. In: Phytoalexins, ed. by J. A. Bailey and J. W. Mansfield, pp. 218-252. Halstead Press, John Wiley \& Sons, New York.

Song, C. Y., Ahn, D. H., Cho, C. H., Chung, J. W. and Nam, S. Y. 2009a. Exporting promotion strategy of grafted cacti. Flower Res. J. 17:67-73.

Song, C. Y., Ahn, D. H., Kim, Y. S., Park, I. T. and Cho, C. H. 2009b. Export market trends of grafted cacti. Flower Res. J. 17:62-66.

Taba, S., Miyahira, N., Nasu, K., Takushi, T. and Moromizato, Z. 2007. Fruit rot of strawberry pear (pitaya) caused by Bipolaris cactivora. J. Gen. Plant Pathol. 73:374-376.

Taylor, J. E. and Whitelaw, C. A. 2001. Signals in abscission. New Phytol. 151:323-339. 